\title{
Forgiveness and Conflict Resolution in Marriage
}

\author{
Frank D. Fincham \\ University at Buffalo, The State University of New York \\ Steven R. H. Beach \\ University of Georgia
}

\author{
Joanne Davila \\ University at Buffalo, The State University of New York
}

\begin{abstract}
Two studies examined whether forgiveness in married couples is associated with better conflict resolution. Study 1 examined couples in their 3rd year of marriage and identified 2 forgiveness dimensions (retaliation and benevolence). Husbands' retaliatory motivation was a significant predictor of poorer wife-reported conflict resolution, whereas wives' benevolence motivation predicted husbands' reports of better conflict resolution. Examining longer term marriages, Study 2 identified three forgiveness dimensions (retaliation, avoidance and benevolence). Whereas wives' benevolence again predicted better conflict resolution, husbands' avoidance predicted wives' reports of poorer conflict resolution. All findings were independent of both spouses' marital satisfaction. The findings are discussed in terms of the importance of forgiveness for marital conflict and its implications for spouse goals. Future research directions on forgiveness are outlined.
\end{abstract}

Paradoxically, those we love are often the ones we are most likely to hurt. It is a rare person who does not, at some point, feel "hurt," "let down," "betrayed," "disappointed," or "wronged" by his or her relationship partner. When interpersonal transgressions occur in marriage they can elicit strong negative feelings and have the potential to disrupt the relationship. Perhaps not surprisingly, spouses report that the capacity to seek and grant forgiveness is one of the most important factors contributing to marital longevity and marital satisfaction (Fenell, 1993). Although scientists have paid remarkably little attention to forgiveness, research on this topic has recently mushroomed (for a bibliography, see McCullough, Exline, \& Baumeister, 1998), stimulated, in part, by interest in how to facilitate forgiveness in counseling/ therapy. Thus, for example, anger has been shown to decline following a forgiveness intervention (e.g., Freedman \& Enright, 1996), thereby setting the stage for possible reconciliation with the transgressor. Such findings suggest that forgiveness may have substantial implications for relationship outcomes (Worthington \& Wade, 1999) and relationship processes such as conflict

Frank D. Fincham and Joanne Davila, Department of Psychology, University at Buffalo, The State University of New York; Steven R. H. Beach, Department of Psychology, University of Georgia.

Joanne Davila is now at Stony Brook University, The State University of New York.

This study was supported by a grant from the Templeton Foundation to Frank D. Fincham and Steven R. H. Beach.

Correspondence concerning this article should be addressed to Frank D. Fincham, Department of Psychology, Park Hall, University at Buffalo, The State University of New York, Buffalo, NY 14260-4110. E-mail: fincham@buffalo.edu resolution. In support of this view, there is initial evidence to suggest that forgiveness is related to relationship well-being (e.g., Fincham, 2000a; Fincham, Paleari, \& Regalia, 2002; McCullough, Rachal, et al., 1998). However, we know little else about forgiveness in marriage. The present studies therefore examine whether forgiveness is related to conflict resolution in marriage.

\section{Conceptualizing Forgiveness}

For a spouse to forgive his or her partner logically requires the spouse to be conscious of being injured/wronged by the partner. Without injury there is nothing to forgive (Enright \& Coyle, 1998). However, it is also necessary for the spouse to believe that the injury was intentionally or, at a minimum, negligently inflicted (Downie, 1965). Forgiveness occurs with the spouse's full knowledge that he or she has a right to feel negatively toward his or her partner and that the partner has no right to expect the spouse's sympathy (North, 1998).

Although the construct of forgiveness has the potential to advance understanding of marital functioning, the lack of a consensual definition has the potential to hinder research. It is therefore worth noting that common to various approaches to forgiveness is the idea of a transformation in which motivation to seek revenge is lessened. Several theoretical statements (e.g., Enright \& Coyle, 1998; Kaminer, Stein, Mbanga, \& Zungu-Dirwayi, 2000; North, 1998) recognize that this core feature immediately distinguishes forgiveness from constructs such as condoning (which removes the offense) and reconciliation (which restores a relationship and is therefore a dyadic process). At the same time, it allows the role of many features previously included in definitions of forgiveness (e.g., intentionality) to be investigated empirically. Whereas condoning or accepting partner transgressions may represent a form of inappropriate 
accommodation $^{1}$ to transgressions, forgiveness represents a willingness to exit from a potential cycle of negative interactions.

Much research builds on the view articulated above but in doing so may be limited by unidimensional conceptualizations of forgiveness. Specifically, most researchers operationalize forgiveness in terms of decreased negative motivation (e.g., revenge, avoidance) toward the transgressor (e.g., McCullough, Rachal, et al., 1998). However, overcoming the resentment, anger, retaliatory impulses, and so forth of unforgiveness may be viewed as reflecting only one dimension of forgiveness, albeit a very important one. Overcoming unforgiveness can be conceptualized, at least in part, as overcoming the negative view of the self implied by the transgressor's behavior, namely, that the victim is not deserving of better treatment. By overcoming the negative portrayal of the self, the victim removes an internal barrier to relatedness caused by the transgression. In turn, motivated avoidance of the transgressor is overcome. Accordingly, overcoming unforgiveness can be viewed as successfully getting past a powerful avoidance motive (avoidance of an unwanted or unacceptable self-image). Perhaps because avoidance goals have an inherent primacy, measurement of forgiveness has focused on this negative dimension (e.g., McCullough, Rachal, et al., 1998), and a great deal of what has been learned about forgiveness rests on inferences made from the absence of a negative motivational orientation towards the harm-doer. For some problem behaviors, overcoming unforgiveness may be critical. For example, if couples are to exit from the "tit for tat" mode of interaction that characterizes much of the problem-focused behavior of distressed couples, overcoming unforgiveness may be particularly important.

Equally fundamental to forgiveness, however, is "an attitude of real goodwill towards the offender as a person" (Holmgren, 1993, p. 34). Forgiveness thus entails a positive or benevolent motivational state towards the harm-doer that is not achieved simply by overcoming the avoidance goal set in motion by an unacceptable self-image or the negative motivational state occasioned by the hurt associated with the transgression. Rather, the positive dimension of forgiveness provides the motivational foundation for approach behavior. Because approach behavior appears to be subsumed by a different motivational system than is avoidance behavior (Gray, 1987), any such positive dimension of forgiveness should be measured directly and not merely inferred from the absence of the negative dimension. Likewise, ambivalence may be a rather different motivational state than is strong negative motivation in the absence of positive motivation (Fincham, Beach, \& Kemp-Fincham, 1997). Accordingly, although the tendency to impose a bipolar structure on constructs in social science is also evident in research on forgiveness, forgiveness cannot be understood completely by studying unforgiveness alone, just as marital quality cannot be fully understood by the study of negative feelings toward the partner or optimism by the study of learned helplessness (Fincham, 2000b). Second, negative and positive dimensions of forgiveness may have different determinants, correlates and consequences. For example, it can be hypothesized that negative and positive dimensions of forgiveness are related to revenge and conciliatory behaviors, respectively.

\section{Implications of Forgiveness for Conflict Resolution}

Conflict resolution is integral to a successful relationship and it can be argued that resentment engendered by partner transgressions is likely to fuel couple conflict and impede successful conflict resolution. In contrast, forgiving the partner for the transgression is one potential means of providing closure with regard to a painful or disturbing relationship event and setting the stage for reconciliation with the transgressor. Forgiveness may therefore have substantial implications for long-term relationship outcomes as well as shortterm patterns of interaction. Specifically, when one partner opts out of the coercive cycle of reciprocal negative interaction, the other should be less likely to continue his or her negative behavior as well. In short, forgiveness may short circuit the use of ineffective conflict strategies likely to emerge from the smoldering embers of an unforgiven transgression.

Thus, one might legitimately ask whether the spouse's failure to forgive partner transgressions that occurred earlier in the marriage is related to the current use of ineffective conflict strategies in the relationship. Specifically, one might hypothesize that a spouse's report of forgiving the partner's transgressions would be inversely associated with the partner's reports of ineffective conflict resolution in the relationship.

\section{Methodological Challenges}

The potential of forgiveness to advance understanding of marriage is limited by overreliance on a single research method. In particular, data on forgiveness in close relationships are oftentimes restricted to examination of associations among variables obtained from a single source. Because forgiveness is usually conceptualized as an intrapersonal variable, albeit with an interpersonal referent, self-reported forgiveness seems quite appropriate. However, it is important to disentangle the source of data for forgive-

\footnotetext{
${ }^{1}$ Forgiveness in the literature on close relationships may appear to be similar to accommodation, or the willingness to respond to potentially destructive partner behavior by inhibiting "tendencies to react destructively" and instead making efforts to "engage in constructive reactions" (Rusbult, Verette, et al., 1991, p. 53). However, accommodation might occur because potentially destructive partner behavior is construed in such a way that its destructive nature is ignored, overlooked, or downplayed, or, when fully recognized, is condoned or excused. Under these circumstances, forgiveness is not a relevant concern. Thus, accommodation cannot be equated with forgiveness because it can occur when necessary conditions for forgiveness (e.g., perceived wrongfulness of transgression, intentionality of partner behavior) are not met as well as when they are met.
} 
ness from the source of data on its correlates. If we obtain from the partner information about likely correlates of selfreported forgiveness, this helps considerably with the "shared method" problem that characterizes much research on forgiveness to date.

In the context of marital interaction and communication, it is also important to determine whether the construct of forgiveness adds conceptual value in a landscape already littered with conceptually overlapping constructs (Bradbury, Fincham, \& Beach, 2000; Fincham \& Bradbury, 1987). Most notably, it is often useful to require that constructs do more than capture variance in commonly used measures of relationship quality. Absent such a requirement, forgiveness may simply function as a proxy index of marital quality. In the case of forgiveness and adaptive conflict behavior, a stringent test of "surplus conceptual value" can be provided by controlling the marital satisfaction of both partners in the relationship.

The present studies therefore attempt to link marital research to a broader literature on forgiveness by examining the underlying structure of the concept. We hypothesized that positive and negative dimensions of forgiveness would be moderately and inversely correlated. A second aim of the studies was to document the relationship between forgiveness and conflict resolution in marriage.

\section{Study 1}

In this study participants answered several questions about their responses to recalled partner transgressions. We predicted that these responses would reflect the two hypothesized forgiveness dimensions and that these dimensions of forgiveness for partner transgressions would, in turn, be related to conflict resolution. The study also provided the opportunity to replicate prior research showing a relation between marital satisfaction and measures of forgiveness.

\section{Method}

\section{Participants}

Fifty-two British couples residing in South Wales participated in the study. Couples were recruited through advertisements in local media for a study on early marriage. All couples were in the $3 \mathrm{rd}$ year of their marriage when they participated in the study and had not been previously married. Husbands averaged 32.6 years of age $(S D=7.7)$ and wives averaged 30.7 years $(S D=6.2)$. The modal spouse, whether husband or wife, had completed a university undergraduate degree. Couples were paid 25 pounds for their participation. Fifty husbands and 52 wives provided complete data for the study.

\section{Procedure and Measures}

Participating couples came to research rooms at the university to participate in the study. As part of a larger study, they completed measures of marital satisfaction, forgiveness, and ineffective conflict strategies.

Marital satisfaction. The Marital Adjustment Test (Locke \& Wallace, 1959) is a frequently used measure of marital quality.
Locke and Wallace reported split-half reliability of .90 and that the MAT discriminated between couples "judged to be exceptionally well-adjusted in marriage by friends who knew them well" and participants who "were known to be maladjusted in marriage" (Locke \& Wallace, 1959, p. 254). It also correlates with clinicians' judgments of marital discord (Crowther, 1985). Scores vary from 2 to 158 , with higher scores reflecting greater satisfaction.

Forgiveness. Forgiveness dimensions were assessed in relation to the incident in the relationship when the respondent "felt most wronged or hurt by your partner." The events reported had occurred an average of 10 months $(S D=16.2)$ and 11.9 months $(S D=19.2)$ previously for husbands and wives, respectively. On a 9-point scale ranging from 1 (very little hurt) to 9 (most hurt ever felt $)$, husbands averaged $5.6(S D=2.1)$ and wives averaged 6.5 $(S D=2.4)$. Spouses indicated the extent to which six statements characterized their response to the transgression. Three statements reflected a benevolent response, for example, "I accepted my partner's humanness, flaws and failures," "I soon forgave my partner," and "I took steps towards reconciliation with my partner (e.g. expressed love, showed concern)." Three items assessed retaliatory responses (e.g., "I thought about how I could get even," "I thought of ways to make my partner regret what s/he did," and "I retaliated or did something to get my own back"). Spouses rated each statement on a 6-point scale anchored by the endpoints 1 (not at all true) and 6 (completely true). Higher scores indicated greater agreement with the statement. Missing data for two husbands precluded their inclusion in regression analyses in which wife reports served as the dependent variable.

Conflict resolution. Conflict resolution was assessed with the Ineffective Arguing Inventory (Kurdek, 1994). This measure is based on descriptions of ineffective arguing found in marital research. It comprises eight items (e.g., "Our arguments are left hanging and unresolved") that spouses rate to indicate the extent to which they characterize their relationship. Kurdek reported high internal consistency for the measure when completed by gay, lesbian, and heterosexual couples (coefficient alpha ranges from .86 to .89$)$ and sizable correlations with relationship satisfaction $(r=-.62$ to -.71$)$. Moreover, the scale was found to be stable over a 1 -year period ( $r \mathrm{~s}=.63$ to .84 ) and predicted declines in relationship satisfaction during this period after initial levels of satisfaction were controlled for. Higher scores on this inventory reflect poorer conflict resolution.

\section{Results and Discussion}

\section{Confirmatory Factor Analysis}

A confirmatory factor analysis was conducted to examine whether the forgiveness items reflected one or two underlying dimensions. Although the ratio of observations to variables in this analysis is less than 10 to 1 , indicating that parameter values should be interpreted with some caution, the results of nested chi-square comparisons nonetheless provide a reliable indication of the differential fit of contrasting structural models. When all six items were used as indicators of a single latent construct, a poor fit was found between the model and the obtained data for both husbands, $\chi^{2}(9, N=50)=29.7, p<.01$, and wives, $\chi^{2}(9, N=52)=$ $32.1, p<.01$. Interestingly, each of the indicator loadings for this unidimensional model was statistically significant (lambda $x$ ranged from -.49 to .70 for husbands and -.64 to .71 for wives). This discrepancy between model fit and 
indicator loadings underscores the need to consider a multidimensional model of forgiveness.

Next we examined a two-factor model in which retaliation and benevolence items were hypothesized to load on separate factors. The two-factor model provided a much better fit of the data for husbands and wives: for husbands, $\chi^{2}(8, N=50)=10.8, n s ;$ for wives, $\chi^{2}(8, N=52)=4.83$, $n s$. However, demonstrating that a two-factor model provides a good fit to the data, whereas a one-factor model does not, is not the same as showing that the two-factor model provides a significantly better fit to the data.

To examine whether a two-factor model is more appropriate than a unidimensional model, we used a model comparison procedure introduced by Bollen (1980). By comparing the hypothesized two-factor model with a model in which the zero-order association between the two dimensions of forgiveness is constrained to be one (thereby positing a single factor), two- and one-factor models can be compared by interpreting the change in chi-square (per change in degrees of freedom) as a chi-square statistic. When the association between positive and negative dimensions was constrained to unity, there was a poor fit to the data: for husbands, $\chi^{2}(9, N=50)=63.5, p<.01$; for wives, $\chi^{2}(9, N=52)=56.3, p<.01$. Removing the constraint to allow separate, covarying positive and negative dimensions resulted in a significant change in chisquare for both husbands and wives: for husbands, $\Delta \chi^{2}(1, N$ $=50)=52.7, p<.001$; for wives $\Delta \chi^{2}(1, N=52)=51.5$, $p<.001$. Accordingly, the two-factor solution provides a significantly better fit to the data than does a single-factor solution. The resulting retaliation (coefficient alphas $=.78$ and .87 for husbands and wives, respectively) and benevolence (coefficient alphas $=.72$ and .78 for husbands and wives, respectively) indices yielded alpha coefficients that were acceptable for research instruments. Higher scores indicated greater retaliation and benevolence, respectively.

\section{Association of Forgiveness With Marital Outcomes and Processes}

Replicating prior findings (e.g., Kurdek, 1994), when correlations were computed separately for husbands and wives, partner reports of ineffective conflict resolution correlated significantly with both partner satisfaction and one's own satisfaction (see Table 1). Also consistent with past research (e.g., Fincham, 2000a), the correlations between spouses' benevolence and marital satisfaction were significant. For husbands, retaliation was also related to marital satisfaction.

As anticipated, partner reports of ineffective conflict resolution correlated negatively with self-reported benevolence for both spouses (for husbands, $r=-.40, p<.01$; for wives, $r=-.36, p<.01$ ) but correlated positively with retaliation for husbands only (for husbands, $r=.46, p<$ .01 ; for wives, $r=.17, n s)$. That is, positive and negative dimensions of forgiveness appear to be related to ineffective conflict resolution in the expected manner. However, this hypothesis remains to be examined in a multivariate context. In particular, it is important to examine both dimensions of forgiveness simultaneously as well as to control for any influence of marital satisfaction. If dimensions of forgiveness are unrelated to partner reports of ineffective conflict resolution after controlling for levels of marital satisfaction, this would suggest that the observed relationship might simply be a function of variance shared with marital satisfaction. Thus, regression analyses were conducted in which the partner's reports of ineffective conflict resolution were predicted from one's own and partner satisfaction and from reports of benevolence and retaliation following the partner transgression. Multivariate models were computed separately for husbands and wives, and in each case, partner reports of ineffective conflict resolution served as the dependent variable and self-reports served as the index of forgiveness dimensions.

The pattern of findings noted at the bivariate level held at the multivariate level in that husbands' self-reported retaliatory impulses were a significant predictor of wives' reported ineffective conflict resolution $(\beta=.31, t=2.1, p<$ $.05)$ even after controlling for the satisfaction of both partners (see Table 2). The benevolence dimension was not a significant predictor for husbands. Conversely, wives' selfreport of benevolence was a significant negative predictor of husbands' reported ineffective conflict resolution $(\beta=$

Table 1

Correlations Among Variables in Study 1 for Husbands (Above Diagonal) and Wives (Below Diagonal)

\begin{tabular}{|c|c|c|c|c|c|c|c|}
\hline Variable & 1 & 2 & 3 & 4 & 5 & $M$ & $S D$ \\
\hline $\begin{array}{l}\text { 1. Partner reports of ineffective } \\
\text { conflict resolution }\end{array}$ & - & $.46^{* *}$ & $-.40 * *$ & $-.36 * *$ & $-.28 *$ & 1.8 & 0.5 \\
\hline 2. Retaliation & .16 & - & $-.36 * *$ & $-.47 * *$ & $-.33^{*}$ & 5.3 & 3.1 \\
\hline 3. Benevolence & $-.36 * *$ & $-.61 * *$ & - & $.35^{*}$ & .26 & 13.8 & 3.1 \\
\hline 4. Own satisfaction & $-.33 *$ & .19 & $.27 *$ & - & $.59 * *$ & 122.2 & 19.4 \\
\hline 5. Partner satisfaction & $-.50 * *$ & -.01 & .09 & $.62 * *$ & - & 128.4 & 15.8 \\
\hline$M$ & 1.8 & 6.0 & 11.9 & 126.9 & 123.5 & & \\
\hline$S D$ & 0.6 & 3.9 & 4.1 & 17.0 & 17.1 & & \\
\hline
\end{tabular}


Table 2

Prediction of Husbands' Reports and Wives' Reports of Ineffective Conflict Resolution in Study 1

\begin{tabular}{|c|c|c|c|c|}
\hline \multirow[b]{2}{*}{ Variable } & \multicolumn{2}{|c|}{$\begin{array}{l}\text { Husbands' reports of } \\
\text { ineffective conflict } \\
\text { resolution }\end{array}$} & \multicolumn{2}{|c|}{$\begin{array}{l}\text { Wives' reports of } \\
\text { ineffective conflict } \\
\text { resolution }\end{array}$} \\
\hline & $\beta$ & $\Delta R^{2}$ & $\beta$ & $\Delta R^{2}$ \\
\hline Overall equation & & .35 ** & & $.29 * *$ \\
\hline Satisfaction & & $.22 * *$ & & .02 \\
\hline Husband & $-.50 * *$ & & -.18 & \\
\hline Wife & .06 & & -.14 & \\
\hline Partner forgiveness dimensions & & $.10^{*}$ & & $.11^{* *}$ \\
\hline Benevolence & $-.35^{*}$ & & -.24 & \\
\hline Retaliation & -.03 & & $.31 *$ & \\
\hline
\end{tabular}

$-.35, t=-2.3, p<.05)$ in the multivariate context, whereas wives' self-report of retaliation was not.

The results of this study suggest that both positive and negative dimensions of forgiveness are associated with couples' conflict resolution. However, the results are limited by both theoretical and methodological considerations. Although the bidimensional structure of forgiveness uncovered represents an important advance in forgiveness research, it may be unduly restricted. Specifically, the negative dimension of forgiveness may itself be bidimensional, as negative responses to partner transgressions may not be limited to engagement with the partner in the form of retaliation. Indeed, McCullough, Rachal, et al. (1998) have argued that feelings of righteous indignation engendered by a transgression result in motivation to seek revenge and see harm come to the transgressor, whereas feelings of hurt following a transgression result in motivation to avoid personal and psychological contact with the offender. Their results provide convincing evidence to support this distinction. It is therefore important to re-examine the results found for retaliation in Study 1 in light of the distinction between retaliation and avoidance.

Two methodological considerations also underline the preliminary nature of the findings obtained in Study 1. First, only couples in the 3rd year of marriage participated in Study 1, raising the question of whether the results would emerge in longer term marriages. Second, the length of time since the transgression was recalled varied widely. A second study was therefore undertaken.

\section{Study 2}

To address the limitations of Study 1, we designed the second study to investigate transgressions that had occurred in the past 6 months of the marriage. Participants were drawn from longer term marriages and answered questions about the transgression that reflected retaliatory, avoidant, and benevolent responses. It was predicted that these responses would reflect the three forgiveness dimensions and that dimensions of forgiveness for partner transgressions would be related to conflict resolution.
Method

\section{Participants}

Participants were 96 couples from the greater Buffalo, New York area who were participating in an ongoing study of family relationships. They were recruited through advertisements and from a local middle school. Four hundred letters were mailed to families of 8th-grade daughters in a local middle school. Families were instructed to return a postage-paid postcard if they were interested in participating. Seventy-seven postcards were returned (19\%), and 31 families who were eligible participated. Advertisements were also placed in local newspapers, on cable television, and in the community. Interested families were asked to call the project. Two hundred forty-eight families were interested and, of them, 65 who were eligible participated. Eligibility criteria included being a two-parent family with an 8th-grade daughter with the ability to read and comprehend questionnaires and participate in computer tasks. Families with daughters with moderate or severe learning disabilities that would impair their performance were excluded. Husbands were 43.1 years old on average $(S D=$ $4.5)$ and predominantly Caucasian $(97 \%)$. Forty-five percent reported graduating from high school and $51 \%$ reported a college or postgraduate education. Mothers were 41.1 years old on average $(S D=4.74)$ and predominantly Caucasian $(98 \%)$. Forty-two percent reported graduating from high school and 57\% reported a college or postgraduate education. Median family income was in the range of $\$ 51,000$ to $\$ 60,000$.

\section{Procedure and Measures}

Participating families attended a laboratory session at the University at Buffalo. During this time, spouses completed measures of marital quality, ineffective arguing, and forgiveness. Families were paid $\$ 75$ for their participation.

Marital satisfaction. As in Study 1, the Marital Adjustment Test (Locke \& Wallace, 1959) was used to measure marital quality.

Conflict resolution. The Ineffective Arguing Inventory (Kurdek, 1994) was again used to assess conflict resolution.

Forgiveness. Forgiveness was assessed in relation to a transgression that occurred in the past 6 months in which the spouse felt "upset, angry or hurt" by something his or her partner said or did. The respondent was asked to recall the event and describe it to the 
Table 3

Correlations Among Variables for Husbands (Above Diagonal) and Wives (Below Diagonal) in Study 2

\begin{tabular}{|c|c|c|c|c|c|c|c|c|}
\hline Variable & 1 & 2 & 3 & 4 & 5 & 6 & $M$ & $S D$ \\
\hline $\begin{array}{l}\text { 1. Partner reports of } \\
\text { ineffective conflict } \\
\text { resolution }\end{array}$ & - & $-.30 * *$ & $.42 * *$ & $.27 * *$ & $-.40 * *$ & $-.50 * *$ & 17.9 & 6.2 \\
\hline 2. Benevolence & $-.34 * *$ & - & $-.47 * *$ & $-.40 * *$ & $.25 *$ & .17 & 15.6 & 2.8 \\
\hline 3. Avoidance & .16 & $-.54 * *$ & - & $.47 * *$ & $-.35^{* *}$ & -.11 & 5.8 & 3.1 \\
\hline 4. Retaliation & .02 & $-.38 * *$ & $.52 * *$ & - & $-.26 * *$ & .10 & 3.9 & 1.7 \\
\hline 5. Own satisfaction & $-.32 * *$ & $.32 * *$ & $-.22 *$ & -.11 & - & $.40 * *$ & 116.2 & 20.8 \\
\hline 6. Partner satisfaction & $-.53 * *$ & .13 & -.06 & .10 & $.40 * *$ & - & 118.8 & 18.5 \\
\hline$M$ & 18.8 & 5.1 & 6.7 & 1.4 & 118.9 & 115.4 & & \\
\hline$S D$ & 5.6 & 1.0 & 3.9 & 0.8 & 19.0 & 21.3 & & \\
\hline
\end{tabular}

research assistant in as much detail as possible. The respondent then rated the amount of hurt he or she experienced. On a 9-point scale ranging from 1 (very little hurt) to 9 (most hurt ever felt), husbands averaged $4.7(S D=2.0)$ and wives averaged $5.8(S D=$ 2.3). Participants also rated nine statements concerning possible avoidant responses (e.g., "I gave him/her the cold shoulder," "I withdrew from my partner," and "I didn't want to have anything to do with her/him"); retaliatory responses (e.g., "I did something to even the score," "I found a way to make her/him regret it," "I retaliated or did something to get my own back"); and benevolent responses (e.g., "I soon forgave my partner," "I am able to act as positively toward my partner now as I was before it happened," and "It was easy to feel warmly again toward your partner"). The participants indicated their ratings on a 6-point scale anchored by 1 (strongly agree) and 6 (strongly disagree). Five husbands failed to provide useable information on this measure and were therefore excluded from the regression equation predicting wives' reports of ineffective arguing.

\section{Results and Discussion}

A confirmatory factor analysis was conducted to examine whether the forgiveness items reflected two or three underlying dimensions. ${ }^{2}$

A two-dimensional model in which forgiveness was conceptualized in terms of a positive and a negative dimension was examined. Specifically, retaliation and avoidance items were used as indicators of a single latent construct, and benevolence items were used as indicators of a second latent construct. A poor fit was found between this twodimensional model and the obtained data for both husbands, $\chi^{2}(26, N=91)=99.1, p<.01$, and wives, $\chi^{2}(27, N=$ $96)=166.8, p<.01$. The discrepancy between model fit and indicator loadings, all of which were significant for both husband and wife analyses, underscored the need to consider a three-dimensional model of forgiveness.

A three-dimensional model in which retaliation, avoidance and benevolence items were used as indicators of separate latent constructs was therefore formally compared with a two-dimensional model. By constraining the association between retaliation and avoidance latent constructs to one (thereby positing a single negative forgiveness dimen- sion), we could compare two- and three-factor models by interpreting the change in chi-square (per change in degrees of freedom) as a chi-square statistic. When the association between retaliation and avoidance dimensions was constrained to unity, there was a poor fit to the data: for husbands, $\chi^{2}(25, N=91)=72.2, p<.01$; for wives, $\chi^{2}(25$, $N=96)=69.9, p<.01$. Freeing the constraint and thus allowing retaliation and avoidance dimensions to represent separate dimensions resulted in a significant change in chisquare for both husbands and wives: for husbands, $\Delta \chi^{2}(1$, $N=91)=37.6, p<.001$; for wives $\Delta \chi^{2}(1, N=96)=$ $14.7, p<.001$. Accordingly, the three-factor solution provides a better fit to the data than does the two-factor model. Subscale scores were computed by summing each set of three items that loaded on retaliation (coefficient alphas $=$ .86 and .85 for husbands and wives, respectively), benevolence (coefficient alphas $=.79$ and .77 for husbands and wives, respectively) and avoidance (coefficient alphas $=.76$ and .80 for husbands and wives, respectively). Higher scores indicated greater retaliation, benevolence, and avoidance, respectively.

Again partner-reported ineffective conflict resolution correlated negatively with self-reported benevolence $(r=-.30)$ and correlated positively with negative forgiveness dimensions for husbands (avoidance $=.42$, retaliation $=.27$ ). For wives only the negative correlation between benevolence and ineffective conflict resolution was obtained $(r=-.34)$. The correlations among the variables are shown in Table 3.

To examine the associations in a multivariate context, separate regression analyses were conducted for husbands and for wives, in which partner reports of ineffective conflict resolution were predicted from one's own and partner satisfaction and from self-reports of benevolence, retalia-

\footnotetext{
${ }^{2}$ The results of Study 1 indicate that a unidimensional model is not viable. This was confirmed when all nine items were used as indicators of a single latent construct; a very poor fit was found between the model and the obtained data for both husbands, $\chi^{2}(27$, $N=91)=153.3, p<.01$, and wives, $\chi^{2}(27, N=96)=166.8$, $p<.01$.
} 
tion, and avoidance (see Table 4). These regression analyses revealed that husbands' self-reported avoidance was the forgiveness dimension to emerge as a significant predictor of wives' reports of ineffective conflict resolution, $\beta=.27$, $t(91)=2.5, p<.05$, after controlling for the satisfaction of both partners. For wives, the pattern of findings noted at the bivariate level held at the multivariate level in that wives' self-reported benevolence was the only forgiveness dimension that predicted husbands' reports of ineffective conflict resolution, $\beta=-.30, t(91)=-2.7, p<.01$.

\section{General Discussion}

The current investigation examines the implications of forgiveness for conflict resolution within marriage and, in doing so, examines the structure of forgiveness. Forgiveness may prove to be an important element of marital transactions precisely because spouses often hurt one another and, in the absence of forgiveness, it may be common for lingering effects to exert their influence on subsequent efforts to resolve marital problems. At a minimum, when avoidance and retaliation are present, they could easily derail efforts at constructive problem solving. That is, if partners believe they are justified in engaging in destructive behaviors during marital problem solving because of unforgiven partner transgressions, it seems likely that this could adversely affect attempts at conflict resolution. In addition, erosion of good will toward the partner seems likely to undermine effortful processes such as accommodation (responding positively to a negative partner behavior) and thus allow more automatic, negative responses to predominate during arguments or disagreements (Rusbult, Verette, Whitney, Slovik, \& Lipkus, 1991; Rusbult, Yovetich, \& Verette, 1996). In the current investigation, husbands' retaliation and avoidance was reliably associated with problematic interactions, whereas wives' lack of benevolence was strongly associated with problematic interactions. Despite an extensive literature on the topography of negative reciprocity and positive marital exchanges, the motivations that give rise to constructive communication and to negative reciprocity have proven elusive (Fincham \& Beach, 1999). In the current investigation, we linked forgiveness with conflict resolution, controlling for both partners' marital satisfaction. The resulting picture suggests a role for forgiveness that goes beyond shared variance with marital satisfaction.

First, we hypothesized that forgiveness was not bipolar but rather had more than one dimension. In Study 1, we used a six-item measure of forgiveness in which three items reflected a benevolent response and three items reflected a retaliatory response. Confirming our hypothesis, we found two underlying dimensions for both husbands and wives. In addition, each of the items loaded on its hypothesized dimension. Accordingly, this study supports the theoretical argument that forgiveness is not unidimensional (see Fincham, 2000a). Following in the footsteps of McCullough, Rachal, et al. (1998), we then investigated the possibility that the negative dimension of forgiveness might itself be divisible into two components. Study 2 found that the nineitem forgiveness measure yielded three distinct and interpretable dimensions of benevolence, retaliation, and avoidance. It therefore appears that forgiveness should not be conceptualized as falling along a single bipolar dimension. Rather, benevolence, or the positive, approach dimension of forgiveness, forms a separate factor from negative dimensions of forgiveness such as retaliation or avoidance. These separate dimensions also had different correlates and performed differently for men and women, further underscoring the importance of treating them as distinct dimensions.

In Study 1 wives' self-reports of benevolence were associated with their husbands' report of conflict resolution. In a multivariate context, the relationship between wife benevolence and husband-reported conflict resolution remained significant when controlling for wives' report of retaliation and both partners' report of marital satisfaction. Accordingly, for wives it was level of benevolence in response to the earlier partner transgression that was most highly related to conflict resolution beyond the influence of satisfaction. For husbands, both self-reported benevolence and selfreported retaliation were significantly related to wife reports

Table 4

Prediction of Husbands' Reports and Wives' Reports of Ineffective Conflict Resolution in Study 2

\begin{tabular}{|c|c|c|c|c|}
\hline \multirow[b]{2}{*}{ Variable } & \multicolumn{2}{|c|}{$\begin{array}{l}\text { Husbands' reports of } \\
\text { ineffective conflict } \\
\text { resolution }\end{array}$} & \multicolumn{2}{|c|}{$\begin{array}{l}\text { Wives' reports of } \\
\text { ineffective conflict } \\
\text { resolution }\end{array}$} \\
\hline & $\beta$ & $\Delta R^{2}$ & $\beta$ & $\Delta R^{2}$ \\
\hline Overall equation & & $.37 * *$ & & $.41 * *$ \\
\hline Satisfaction & & $.24 * *$ & & $.22 * *$ \\
\hline Husband & $-.48 * *$ & & $-.43 * *$ & \\
\hline Wife & -.04 & & -.10 & \\
\hline Partner forgiveness dimensions & & $.07 *$ & & $.11 * *$ \\
\hline Benevolence & $-.30 * *$ & & -.04 & \\
\hline Avoidance & -.11 & & $.27 *$ & \\
\hline Retaliation & .02 & & .10 & \\
\hline
\end{tabular}


of conflict resolution. However, in a multivariate context, only the relationship between husband-reported retaliation and wife's report of ineffective conflict resolution was significant after considering the effects of both partners' satisfaction.

In Study 2, wives' benevolence was again the only significant correlate of husbands' reported conflict resolution, whereas for husbands, avoidance was the dimension that accounted for the greatest unique variance in wives' reports of ineffective conflict resolution. Together, the studies suggest that lower levels of the wife's benevolence may be reliably associated with difficulty resolving conflicts, whereas higher scores on the negative dimensions of forgiveness for husbands, particularly avoidance, may be strongly associated with difficulty resolving conflicts. Because the patterns emerged for couples who were in relatively young relationships as well as for couples who were in more established relationships, the pattern of results supports the view that forgiveness of partner transgression may be important in accounting for problematic interactions in both early and mid-stage marriage.

It is important to note that the gender-related pattern of findings in relation to partner report of ineffective conflict resolution was consistent across the two studies. It is possible, however, that these reflect more basic gender differences in response to intimate partner conflict rather than fundamentally different reactions to forgiveness for men and women. Women are less likely to avoid and more likely to engage problematic areas in need of discussion than are men (Heavey, Layne, \& Christensen, 1993). As a result, it is often the wife who raises problematic issues for discussion and who takes on the role of pursuing problem discussions, whereas the husband may more often be in the role of the person withdrawing from the discussion. In this context, factors that increase husband withdrawal might be particularly likely to fuel a destructive demand-withdraw cycle, leading to increased reports by wives of ineffective arguing. Conversely, factors that increase the wife's likelihood of using a negative start-up (responding to partner neutral affect with negative affect; Gottman, 1998) or decrease her willingness to accommodate to partner avoidance could be particularly likely to lead husbands to report greater levels of ineffective arguing.

In the current studies, husbands who endorsed greater retaliation (Study 1) or withdrawal (Study 2) in response to partner transgressions had wives who reported higher levels of ineffective conflict resolution in the relationship. Conversely, wives who endorsed lower benevolence in response to partner transgressions had husbands who reported higher levels of ineffective arguing. If the current conjecture is correct, the results obtained may reflect average gender differences in conflict rather than gender differences in forgiveness. However, for both husbands and wives, forgiveness may play an important role in setting the stage for handling future conflict that is independent of the effect of relationship satisfaction.

Although the present study does not permit causal inferences, we can nonetheless speculate why lack of forgiveness of past partner transgressions might play an important role in the way couples manage current disagreement and conflict. One possibility suggested by general "spread of activation" (Collins \& Loftus, 1975) is that unresolved transgressions may prime response tendencies or higher level approach and avoidance goals with regard to the partner. Any subsequent relationship disagreement would then require a lower threshold to activate unforgiveness associated with the original transgression. Similarly, unresolved partner transgressions may lead to frequent cognitive rehearsals, potentially increasing the strength of the connection between the partner and retaliation or avoidance goals, perhaps allowing the partner to eventually automatically elicit these reactions (see McCullough, Rachal, et al., 1998).

Alternatively, past transgressions that have not been fully forgiven may be associated with implemental intentions (Gollwitzer \& Brandstatter, 1997). In this view, at the time of the transgression the individual may form an intention to act in a particular manner toward the partner should an opportunity arise. For example, an individual may decide to make sure his or her partner "does not get away with anything" or "doesn't get more than they deserve." Such implemental intentions increase the likelihood of reacting to an opportunity to engage in the intended behavior (Gollwitzer \& Brandstatter, 1997). At the same time, such implemental intentions could undermine any intention to implement important conflict regulating behaviors and thus undermine effortful accommodative responses, leading to more destructive arguments.

\section{Future Research Directions}

The current study does not test the possibility of changes in particular interactional behaviors as a function of decreased benevolence or increased avoidance or retaliation. Future research might therefore examine interactional behavior to see how forgiveness influences particular behaviors such as wives' soft start-up (i.e., wives raise the problem in a manner that is less harsh) or husbands' use of withdrawal (i.e., husbands turn away or stop attending to the partner). Likewise, the current study does not directly examine inhibition of accommodative goals or priming of avoidance and retaliatory goals as a function of different levels of forgiveness. Future research might better examine the ease with which particular approach and avoidance goals can be primed as a function of forgiveness of old hurts and transgressions. Likewise, it would be useful to examine the role of forgiveness in influencing response to common accommodative dilemmas of the sort that may arise in dealing with disagreements and conflicts of interest (e.g. Holmes, 2002).

Future research is also needed to address several limitations of the present studies. First, the forgiveness dimensions identified should be considered tentative until they are replicated with a larger sample. Second, two factors, the moderate severity of reported transgressions and the nonrandom nature of the samples, caution against generalizing the results to clinic couples in the absence of research on 
clinic samples. For example, it is quite possible that both the structure of forgiveness and its correlates differ for moderate (e.g., spouse embarrasses partner in front of friends) as compared with severe transgressions (e.g., infidelity, physical abuse). In a similar vein, a spouse may overcome minor transgressions in the marriage in a way that does not involve an explicit decision to forgive the partner. At the same time, Study 1 examined more hurtful transgressions, and Study 2 examined less hurtful transgressions. Thus, the convergence of findings across the two studies suggests that, at least within a broad mid-range of transgression severity, there is consistency in the structure and correlates of forgiveness. Third, the present studies, like most on forgiveness, do not analyze changes in motivation (see McCullough, Fincham, \& Tsang, 2003, for an exception), and future research using such analyses would better test the prevailing conceptualization of forgiveness as a motivational transformation.

\section{Implications for Application and Public Policy}

As expected, forgiveness dimensions accounted for variance in marital satisfaction, confirming their potential importance for marital therapists. Since Close (1970) first published a case study on forgiveness in counseling, 14 forgiveness intervention studies have been conducted. Worthington, Sandage, and Berry (2000) summarized these interventions (delivered to 393 participants) by showing that there is a linear dose-effect relationship for the effect sizes they yield. Specifically, clinically relevant interventions (defined as those of 6 or more hours duration) produced a change in forgiveness (effect size $=.76$ ) that is reliably different from zero, with nonclinically relevant interventions (defined as 1 or $2 \mathrm{hr}$ duration), yielding a small but measurable change in forgiveness (effect size $=.24$ ).

In the present study, forgiveness dimensions accounted for variance in destructive interactional processes that was not accounted for by measures of relationship satisfaction. Accordingly, the results suggest that in order to promote more effective conflict resolution, it may be important to better understand not only the nature of the association between forgiveness and relationship satisfaction but also the processes that promote forgiveness of partner transgressions. Indeed, because anger has been shown to decline following a forgiveness intervention (e.g., Freedman \& Enright, 1996), the current results should encourage efforts to develop forgiveness interventions that might be tested as precursors to marital therapy when anger and resentment related to past partner transgressions are central to the presenting problem.

Finally, it is noteworthy that all but two of the intervention studies conducted to date use a group format and tend to examine interventions that are largely psychoeducational. Hence it is not surprising that explorations of unforgiveness as a public health problem (e.g., Fincham \& Kashdan, in press) stress alternative vehicles (e.g., the Internet, mass media) for delivery of forgiveness interventions. The importance of empirically evaluating the efficacy of such broad-scale interventions is emphasized by their potential to influence large numbers of couples whose needs cannot be addressed through traditional individual or group therapies owing to lack of resources.

\section{References}

Bollen, K. A. (1980). Issues in the comparative measurement of political democracy. American Sociological Review, 45, 370390.

Bradbury, T. N., Fincham, F. D., \& Beach, S. R. H. (2000). Research on the nature and determinants of marital satisfaction: A decade in review. Journal of Marriage and the Family, 62, 964-980.

Close, H. T. (1970). Forgiveness and responsibility: A case study. Pastoral Psychology, 21, 19-25.

Collins, A. M., \& Loftus, E. F. (1975). A spreading-activation theory of semantic processing. Psychological Review, 82, 407428.

Crowther, J. H. (1985). The relationship between depression and marital adjustment: A descriptive study. The Journal of Nervous and Mental Disease, 173, 227-231.

Downie, R. S. (1965). Forgiveness. Philosophical Quarterly, 15, 128-134.

Enright, R. D., \& Coyle, C. T. (1998). Researching the process model of forgiveness within psychological interventions. In E. L. Worthington (Ed.), Dimensions of forgiveness: Psychological research and theological perspectives (pp. 139-161). Philadelphia: Templeton Press.

Fenell, D. (1993). Characteristics of long-term first marriages. Journal of Mental Health Counseling, 15, 446-460.

Fincham, F. D. (2000a). The kiss of the porcupines: From attributing responsibility to forgiving. Personal Relationships, 7, $1-23$.

Fincham, F. D. (2000b). Optimism and the family. In J. Gillham (Ed.), The science of optimism and hope (pp. 271-298). Philadelphia: Templeton Press.

Fincham, F. D., \& Beach, S. R. H. (1999). Conflict in marriage: Implications for working with couples. Annual Review of Psychology, 50, 47-77.

Fincham, F. D., Beach, S. R., \& Kemp-Fincham, S. I. (1997). Marital quality: A new theoretical perspective. In R. J. Sternberg \& M. Hojjat (Eds.), Satisfaction in close relationships (pp. 275304). New York: Guilford Press.

Fincham, F. D., \& Bradbury, T. N. (1987). The assessment of marital quality: A reevaluation. Journal of Marriage and the Family, 49, 797-809.

Fincham F. D., \& Kashdan, T. B. (in press). Facilitating forgiveness. In P. A. Linley \& S. Joseph (Eds.), International handbook of positive psychology in practice: From research to application. Hoboken, NJ: Wiley.

Fincham, F. D., Paleari, G., \& Regalia, C. (2002). Forgiveness in marriage: The role of relationship quality, attributions and empathy. Personal Relationships, 9, 27-37.

Freedman, S. R., \& Enright, R. D. (1996). Forgiveness as an intervention goal with incest survivors. Journal of Consulting and Clinical Psychology, 64, 983-992.

Gollwitzer, P. M., \& Brandstatter, V. (1997). Implementation intentions and effective goal pursuit. Journal of Personality and Social Psychology, 73, 186-199.

Gottman, J. M. (1998). Psychology and the study of marital processes. Annual Review of Psychology, 49, 169-179.

Gray, J. A. (1987). The psychology of fear and stress. Cambridge, England: Cambridge University Press. 
Heavey, C. L., Layne, C., \& Christensen, A. (1993). Gender and conflict structure in marital interaction: A replication and extension. Journal of Consulting and Clinical Psychology, 61, 16-27. Holmes, J. G. (2002). Interpersonal expectations as the building blocks of social cognition: An interdepence theory perspective. Personal Relationships, 9, 1-26.

Holmgren, M. R. (1993). Forgiveness and the intrinsic value of persons. American Philosophical Quarterly, 30, 342-352.

Kaminer, D., Stein, D. J., Mbanga, I., \& Zungu-Dirwayi, N. (2000). Forgiveness: Toward an integration of theoretical models. Psychiatry, 63, 344-357.

Kurdek, L. (1994). Conflict resolution styles in gay, lesbian, heterosexual nonparent, and heterosexual parent couples. Journal of Marriage and the Family, 56, 705-722.

Locke, H. J., \& Wallace, K. M. (1959). Short marital adjustment prediction tests: Their reliability and validity. Marriage and Family Living, 21, 251-255.

McCullough, M. E., Exline, J. J., \& Baumeister, R. F. (1998). An annotated bibliography of research on forgiveness and related concepts. In E. L. Worthington (Ed.), Dimensions of forgiveness: Psychological research and theological perspectives (pp. 193317). Philadelphia: Templeton Press.

McCullough, M. E., Fincham, F. D., \& Tsang, J. (2003). Forgiveness, Forbearance, and Time: The Temporal Unfolding of Transgression-Related Interpersonal Motivations. Journal of Personality and Social Psychology, 84, 540-557

McCullough, M. E., Rachal, K. C., Sandage, S. J., Worthington, Jr. E. L., Brown, S. W., \& Hight, T. L. (1998). Interpersonal forgiving in close relationships: II. Theoretical elaboration and measurement. Journal of Personality and Social Psychology, 75 (6), 1586-1603.

North, J. (1998). The "ideal" of forgiveness: A philosopher's exploration. In R.D. Enright \& J. North (Eds.), Exploring forgiveness (pp. 15-45). Madison, WI: University of Wisconsin Press.

Rusbult, C. E., Verette, J., Whitney, G. A., Slovik, L. F., \& Lipkus, I. (1991). Accommodation processes in close relationships: Theory and preliminary evidence. Journal of Personality and Social Psychology, 60, 53-78.

Rusbult, C. E., Yovetich, N. A., \& Verette, J. (1996). An interdependence analysis of accommodation processes. In G. J. O. Fletcher \& J. Fitness (Eds.), Knowledge structures in close relationships: A social psychological approach. Mahwah, N. J.: Lawrence Erlbaum.

Worthington, E. L., Jr., Sandage, S. J., \& Berry, J. W. (2000). Group interventions to promote forgiveness: What researchers and clinicians ought to know. In M. E. McCullough, K. Pargament, \& C. Thoreson (Eds.), Forgiveness: Theory, research, and practice (pp. 228-253). New York: Guilford Press.

Worthington, E. L., Jr., \& Wade, N. G. (1999). The psychology of unforgiveness and forgiveness and implications for clinical practice. Journal of Social and Clinical Psychology, 18, 385-418.

Received July 10, 2002

Revision received January 28, 2003

Accepted June 17, 2003

\section{Low Publication Prices for APA Members and Affiliates}

Keeping you up-to-date. All APA Fellows, Members, Associates, and Student Affiliates receive-as part of their annual dues-subscriptions to the American Psychologist and APA Monitor. High School Teacher and International Affiliates receive subscriptions to the APA Monitor, and they may subscribe to the American Psychologist at a significantly reduced rate. In addition, all Members and Student Affiliates are eligible for savings of up to $60 \%$ (plus a journal credit) on all other APA journals, as well as significant discounts on subscriptions from cooperating societies and publishers (e.g., the American Association for Counseling and Development, Academic Press, and Human Sciences Press).

Essential resources. APA members and affiliates receive special rates for purchases of APA books, including the Publication Manual of the American Psychological Association, and on dozens of new topical books each year.

Other benefits of membership. Membership in APA also provides eligibility for competitive insurance plans, continuing education programs, reduced APA convention fees, and specialty divisions.

More information. Write to American Psychological Association, Membership Services, 750 First Street, NE, Washington, DC 20002-4242. 